\title{
The Design of the Automatic Control System of the Gripping-Belt Speed in Long-Rootstalk Traditional Chinese Herbal Harvester
}

\author{
Jinxia Huang*, Junfa Wang, and Yonghong Yu \\ Institute of Mechanical Engineering, Jiamusi University, Jiamusi, \\ Heilongjiang Province, P.R. China 154007, \\ Tel.:13836641830 \\ hjxlcj2006@sina.com
}

\begin{abstract}
This article aims to design a kind of gripping-belt speed automatic tracking system of traditional Chinese herbal harvester by AT89C52 single-chip micro computer as a core combined with fuzzy PID control algorithm. The system can adjust the gripping-belt speed in accordance with the variation of the machine's operation, so there is a perfect matching between the machine operation speed and the gripping-belt speed. The harvesting performance of the machine can be improved greatly. System design includes hardware and software.
\end{abstract}

Keywords: gripping-belt speed, traditional chinese herbal harvester, single-chip microcomputer, fuzzy PID.

\section{Introduction}

China is one of the most abundant and productive countries in the world. Nowdays, there are more than 500 kinds of Chinese traditional herbals which have already been gained successfully by man-made planting among 11146 kinds of medical plants. There are more than 1000 kinds of Chinese medicinal herbs which are popular in the market, about $25 \%$ of which are medicinal herbs of roots type (Yang JunJie et al., 2007). In recent years, the seven seas advocate "to return back into the nature", rising a green consumption upsurge, which makes a sharp demand for herbal medicine in the international market. In the global pharmaceutical market, the annual trading volume of the natural plant medicine is nearly $\$ 30$ billions, and is increasing at an annual rate of $20 \%$ (Yang Yong et al., 2005).

\section{The Actual Problems of the Roots Herbs Planting}

Various herbs will be mainly produced by man-made planting because of the national disorderly digging forbidden and awareness for environment protecting. At present, long-rootstalk traditional chinese herbal' planting area has been over 250 million mu

\footnotetext{
"Corresponding author.
} 
all over china including northeast, northwest, southwest ,etc. The actual problem of bottleneck herbs planting lies in harvesting which is mainly manual digging or manual picking after digging with deep loosening machines, so the disadvantages are high labor intensity, low efficiency and high loss of harvest. Besides, the time of chinese medicine herbal harvest is strictly required, or it will greatly influence the quality of the herbals and the planters' income. The problems above result in moratorium area of chinese traditional herbal planting. Therefore, the harvester development, especially long rootstalk chinese traditional herbals' harvester is an urgent task for us.

\section{Hardware Design of Control System}

Rubber gripping-belt is one of the core parts for long-rootstalk chinese traditional herbal harvester, as shown in Fig1. Whether the gripping-belt speed is matched with its machine's operation or not is the most important factor which affects the productivity and operating quality during the harvesting. At present, the gripping-belt speed regulation of harvester is controlled by operator's manual gearshift and
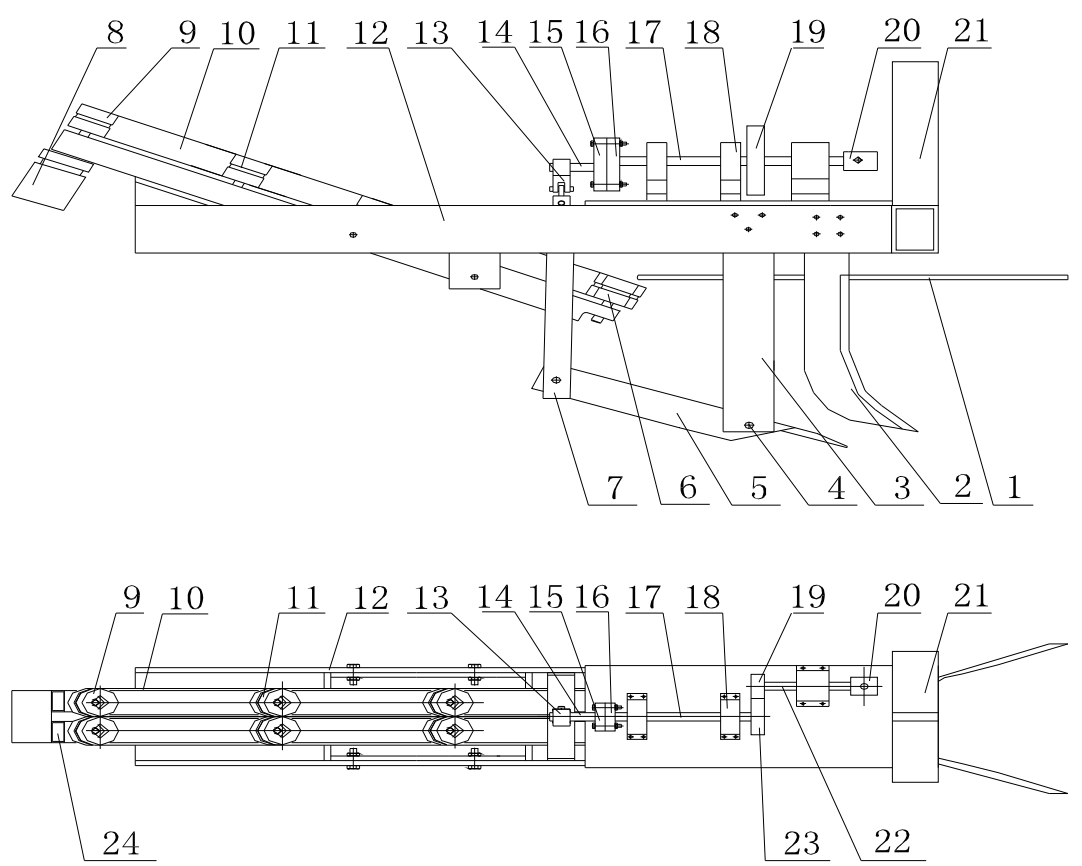

1 sub-seeding device 2 colter 3 fore-stock 4 bolt 5 vibration digging shovel 6 gripping-wheel 7 vibration rod 8 hydraulic motor 9 driver 10 gripping-belt 11 tensioning wheel 12 chassis 13 vibration block 14 back partial axle 15 back partial flange 16 front partial flange 17 front partial axle 18 front partial pedestal 19 chain wheel 20 gimbals 21 suspension bracket

Fig. 1. Long roots of chinese herbal medicines schematic harvester 
adjusting hydraulic contin uously variable transmission according to the machine's operating speed, which will cause large speed-fluctuations and controlling inaccuracy as well as untimely operation. The system chooses single-chip microco mputer as the control center, and it is directed by fuzzy PID control, making actuators and grippingbelt speed into a closed-loop system, so it can achieve an automatic adjusting system in order to satisfy the requirements of the harvester operation.

The control system is used for measuring the current machine operation speed and gripping-belt speed. According to the fuzzy PID control algorithm, it can deal with the measured values, produce the corresponding control signal and drive electromagnetic regulating speed valve into a movement state, thus gripping-belt speed can be changed by tracking the machinery operation speed. The control system mainly takes an 8-bit AT89C52 single-chip microcomputer as a main control unit, periphery circuit includes input and output signal processing circuits, $4 * 4$ keyboard and LED display and so on. The hardware system structure diagram is shown in Fig2:

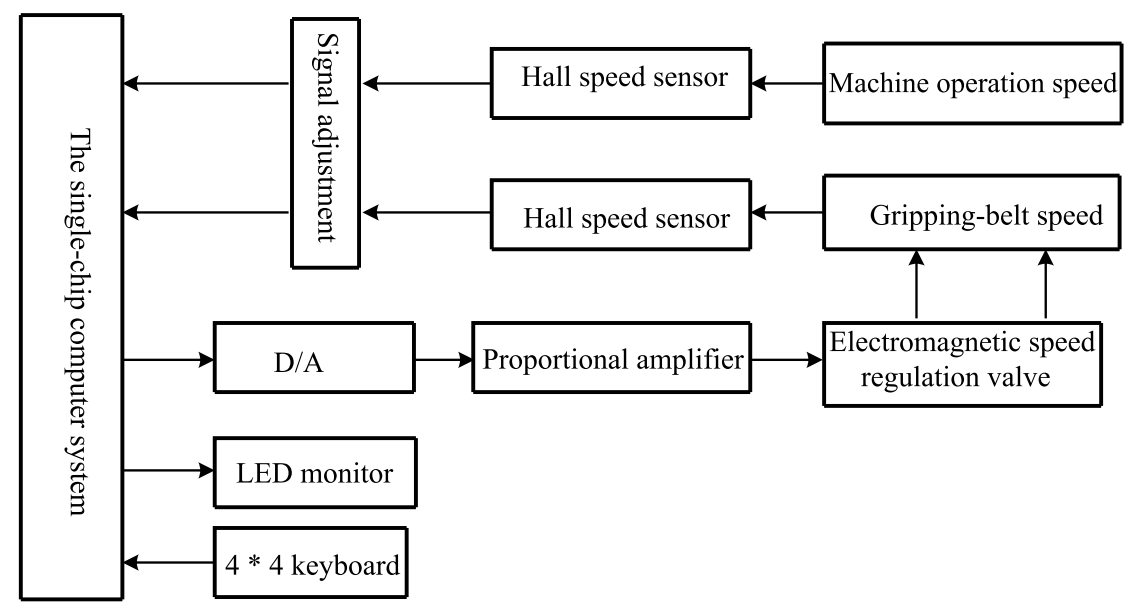

Fig. 2. Automatic control system hardware diagram

\subsection{Detection Methods of Machine Operation Speed and Gripping-Belt Speed}

Currently there are mainly three kinds of methods to measure rotative speed in industry: electromagnetic rotative speed sensor, incremental type optical coded disc sensors and hall switch speed sensors. But the first two kinds aren't suitable for its condition after analysis of the characteristics of the three sensors and poor working condition of herbal harvester. By contrast, the output signal's voltage amplitude of hall switch sensors is not influenced by rotative speed. It has high interference ability to prevent from electro magnetic wave, convenient installation and easy maintenance, simple struc ture, small volume, sensitive, long service life, high reliability, undertaking high impact resistance, resistance to shock. Therefore, hall switch speed sensors are more suitable for this kind of environment (Zhang Xin et al., 2002). Switch type hall speed sensor working principle is shown as Fig3. 


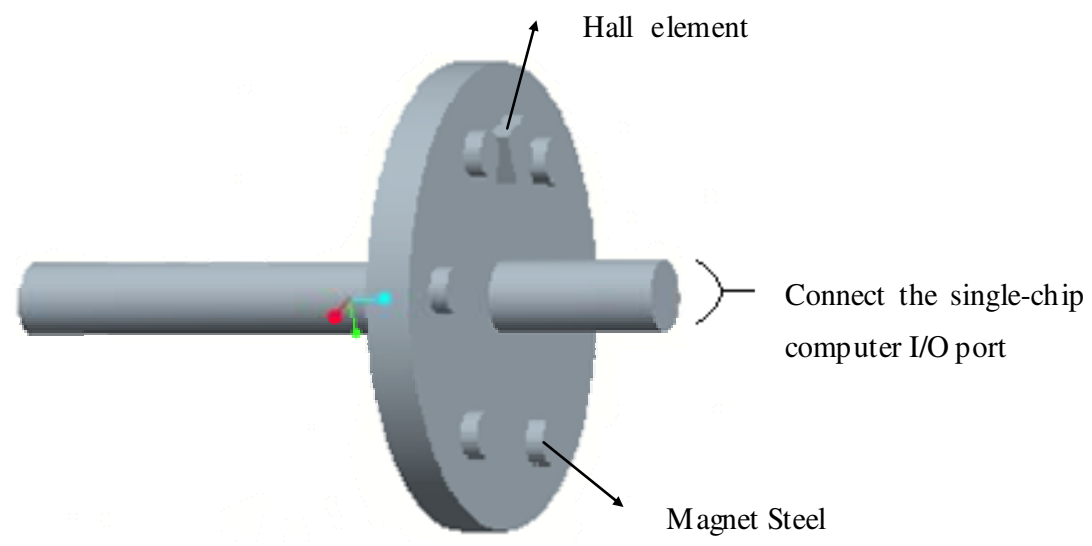

Fig. 3. The principles of hall sensors

The magnetic steel is well-proportioned conglutinated on the surface of the rotator, and hall switch integrated circuit is installed on a fixed location. When the rotator is running each lap, the circuit will output a pulse signal (or multiple pulse signals) each lap, the output pulse of hall switch circuit is directly proportional to its speed. After having finished measuring the sum of its pulse in unit time, the speed of this rotator can be obtained. According to the requirement of the system, the sensor's detecting elements are respe ctively installed on the transmission shafts which are located inside of the machine and gripping-belt's drive shaft, measuring speed. When transmis sion shafts turn a certain angle every time, hall sensor produces a pulse. According to the transmission ratio between transmission shaft and the drive shaft, we can work out the

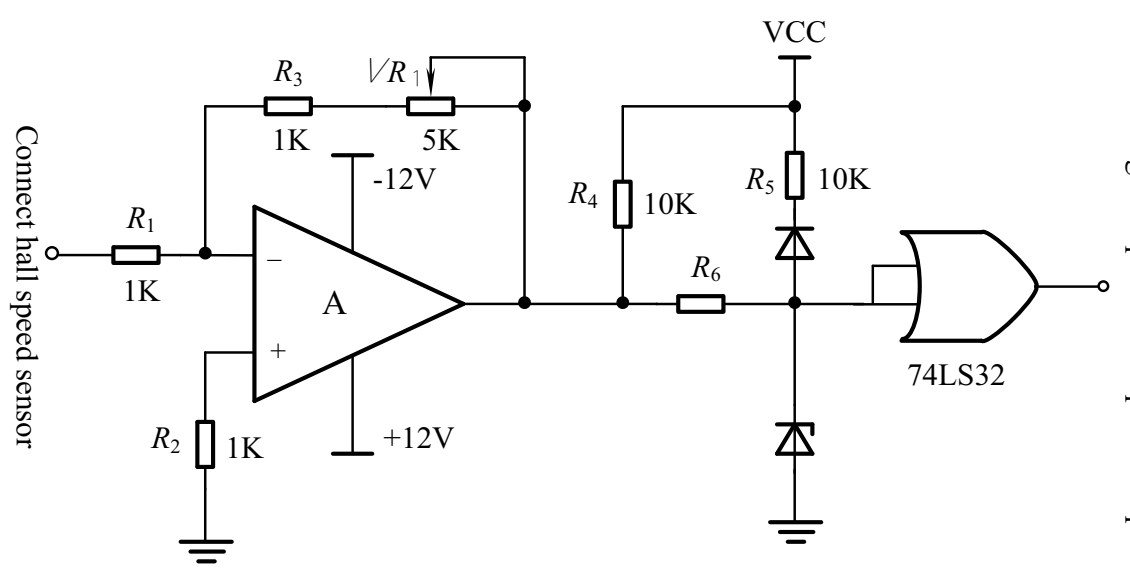

Fig. 4. Velocity measurement circuit 
sum of pulse which produced by the drive shafts when they turn the same angle. After the detected pulse signal of hall sensor should be dealt by shaping circuit as shown in Fig4, we can obtain a standard pulse with its amplitude $+5 \mathrm{~V}$. There's no need for A/D conversion, standard pulse can be counted relying on directly input the single-chip microco mputer's pins, which can work out machine operation speed and grippingbelt rotational speed.

\subsection{The Single-Chip Microcomputer Application System}

AT89C52 single-chip microcomputer is a kind of low voltage, high perfo rmance CMOS 8-bit type which is produced by American ATMEL company. It contains an $8 \mathrm{~K}$ bytes read-only memory (ROM) which can be repeated erasing and writing and a 256 bytes random access memory (RAM), and it is produced by ATMEL company adopting the high density, nonvolatile mem ory technology (Wang ZhiGang, 2004).

\subsection{DAC Converter}

The actuator of this design is electromagnetic regulating speed valve. Its control voltage regulation is for $0 \mathrm{~V} \sim 10 \mathrm{~V}$. The signal which is output by single-chip microcomputer may control the electromagnetic valve after DAC convert and proportional amplifying. The system employ DAC0832 digital-to-analog converter for the advantages of low cost, simple interface and easy conversion control.

\subsection{Input/Output Devices}

Keyboard and display unit can be controlled by chip 8279 . It can complete the function of dialogue between human and machine through the keyboard. The operator sends the control instruction to the chip and input necessary data. Display unit is a type of 4-bit LED display, using dynamic display. It can display machine operation speed and the gripping-belt current speed after analysis of the single-chip microcomputer's calculation.

\subsection{The Software Design of Automatic Control System}

The function of the main program is to initialize the working state of single-chip microcomputer and other chips, simultaneously organize and invoke every subprogram to complete control function according to predet ermined instruction demand. The following is the specific program functions:

(1) The single-chip microcomputer and other chips are initialized.

(2) Invoke subprogram of gripping-belt speed measuring.

(3) The speed information on LED display for driver reference.

(4) The data of the machine's operation speed enters into the main program after the measuring subprogram of machine operation.

(5) Examine the match extent between the machine operation speed and the gripping-belt speed. It invokes the subprogram which control electromagnetic valve adjusted correspondingly. 
Language $\mathrm{C}$ is used in this program, which improves the design efficiency relatively to assembly language, source program's strong readability and easy maintenance. The main program flowchart is shown in Fig5:

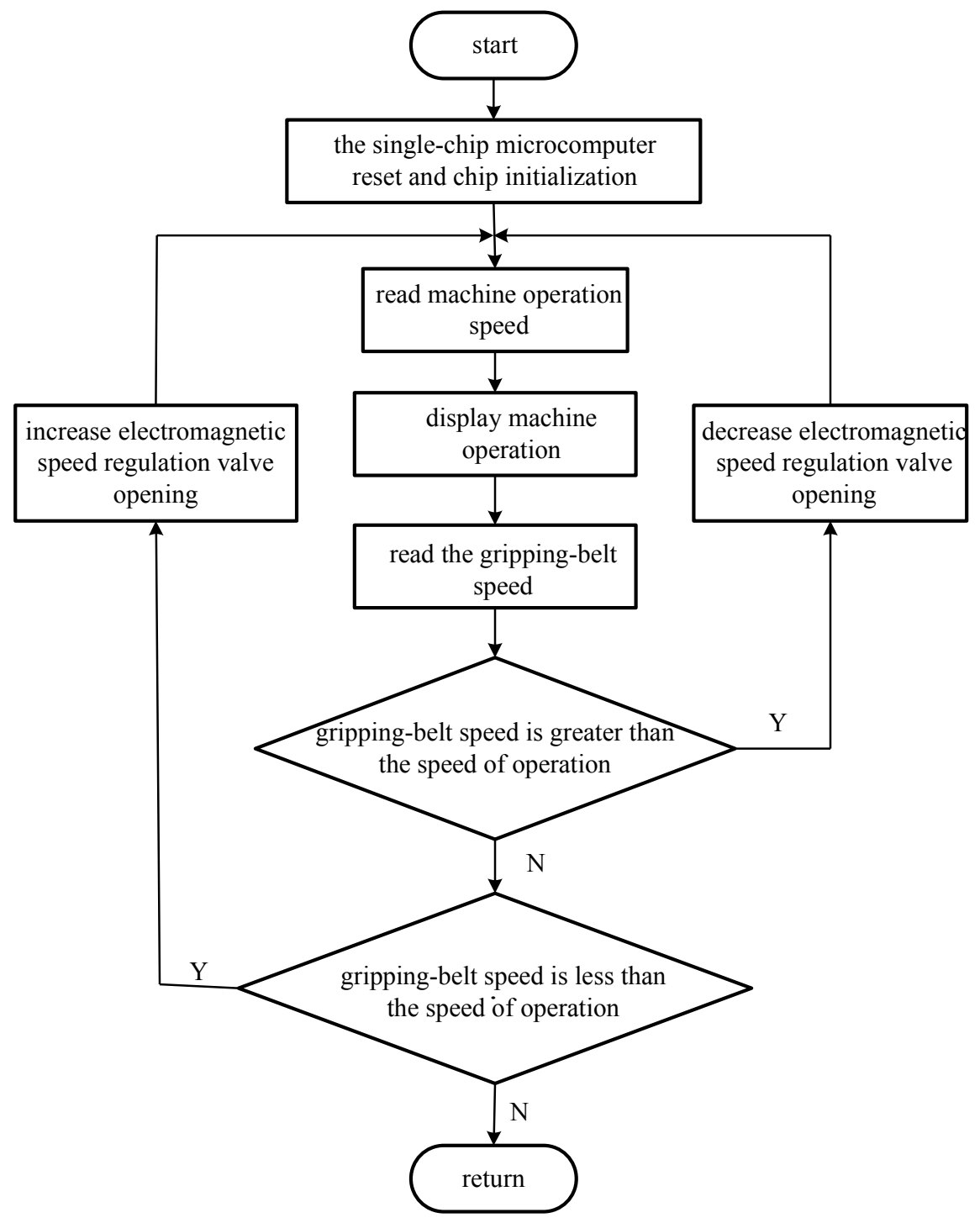

Fig. 5. Main program flowchart of automatic control system

\section{The Algorithm Design of Automatic Control}

Based on the characteristics of the system and the control requirements, the fuzzy PID control algorithm is adopted. The controller structure is shown in Fig6: 


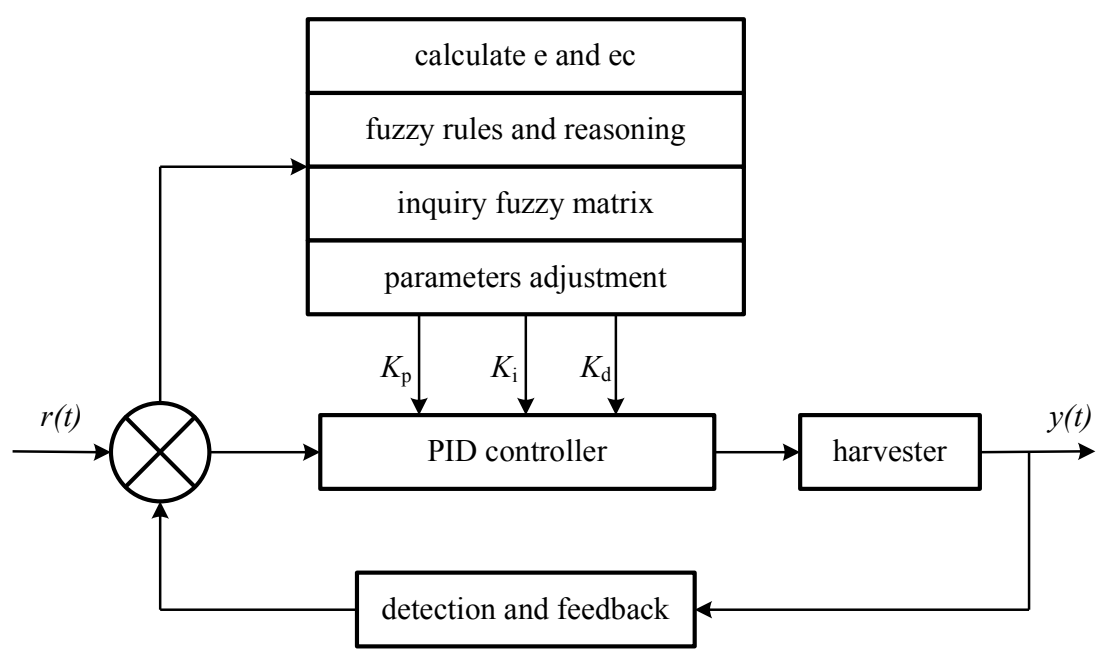

Fig. 6. Fuzzy PID control structure

Fuzzy PID controller can carry PID parameters self-regulating online for PID controller by fuzzy controller. The first task is to find out the fuzz relationship between three parameters ( $\mathrm{kd}$, ki and $\mathrm{kp}$ ) of PID and deviation change rate (EC), and then, through constant detecting the deviation (E) and its change rate in operation. According to the fuzzy control theory, the parameters above can be modified online to meet the need of the different requirements of controller parameters when different deviation and change occur (Han JunFeng, 2003).

The deviation value $\mathrm{E}$ with real time between gripping-belt speed and machine speed, as well as its change rate EC both input variables into the fuzzy controller. Electromagnetic speed regulation valve can speed up or slow down by means of adjusting the output of fuzzy controller, thus a double input and single output fuzzy controller are established and speed control can be achieved.

\section{Conclusion}

Based on AT89C52 single-chip microcomputer, the control system is designed in accordance with the detected machine operating speed to control the speed of gripping-belt. It has a simple structure and be easy to be deal with. The control system of the chinese herbal medicine harvest can make the gripping-belt speed automatically match according to the change of machine's speed to achieve the perfect cooperation. Based on the debugging of each subsystem as well as the whole system, the results showed that the control system is stable in operation, simple operating and worthy of further research and development. The design purpose is achieved successfully. 


\section{References}

JunJie, Y., Jian, Y., HaiXia, Y.: Henan herbs grow resource survey. Journal of modern medicine research and practice 21(5), 13-14 (2007)

Yong, Y., ShiMin, Y.: China, eu, Japan's medicinal plants. Norms and pharmaceutical 14(4), 14-17 (2005)

Xin, Z., ShenLong, C.: New hall-effect sensor characteristics and application in the measurement and control. Journal of university Daniel 21(10), 28-31 (2002)

ZhiGang, W.: MCU application technology and training. Tsinghua University Press, Beijing (2004)

JunFeng, H., et al.: The fuzzy control technology. Chongqing University Press, Chongqing (2003)

Science and Technology Project Supported by National the 11th five- year plan (2006BAD11A07-6)

Key Science and Technology Project Supported by Jiamusi University (LZJ2008-001) 